\title{
A Research on the Application of Three-D Planning of EIS in Manufacturing Industry
}

\author{
Nan Ren', Yixin $\mathrm{Li}^{2}$, Jianyi $\mathrm{Liu}^{3}$ and Hong Miao ${ }^{4}$ \\ ${ }^{1.3 .4}$ School of Economic and Management, Jiangsu University of Science and Technology, \\ Zhenjiang 212003, Jiangsu, P.R. China \\ rennan hb@sohu.com bjliujianyi@163.com miaohong98@hotmail.com \\ ${ }^{2}$ Business Administration School, Jiangsu University, Zhenjiang 212003, Jiangsu, \\ P.R. China lyx@ujs.edu.cn
}

\begin{abstract}
Many manufacturing enterprises implement EIS according to the principle- "planning totally, implementing step by step", but the effect of such implementation after the detailed function planning was not satisfying as expected. This paper analyze the reasons from the failure, find out that only putting particular emphasis in one function usually causes that the step-by-step implementation can't be realized well. It also put forward that only three planning levels from function, data and implementing are conducted together, three-D support can be formed effectively and the performance can be guaranteed. Meanwhile it discuss the principle of threeD planning, analyze the way of collaboration among the three levels, and suggest the planning modes of the key-point radiation and main clue, both of which can guarantee the integration goal through the implementation in parts and then the realization on whole. As a result, with comprehensive consideration, the proposed planning can guarantee the EIS to be realized, based on the relationship among function, data and implementing and information resources planning.
\end{abstract}

Keywords: Enterprise information system (EIS), Key-point radiation mode, Main clue mode, Enterprise model, Data Integration, Enterprise software solutions

\section{INTRODUCTION}

Many manufacturing enterprises can't get expected effect of the implementation after the detailed function planning when implementing EIS. This paper aimed at the basic information environment for enterprise informationization, related the construction of EIS and its business operations, put forward the successful implementation of EIS must obey the 3-D planning on functions, data and implementation, discussed and suggested how to develop such planning. 


\section{PRINCIPLES OF THREE-D PLANNING}

The start of three-D planning is to make the future enterprise informationization implement work in the steady progress and can be controlled. While planning, the connection between direct of upper level activity to bottom layer activity and support of bottom layer activity to upper level activity in the process of portrait informationization could be considered. And we also should emphasize the areas in the informationization work of transverse enterprises and its corresponding relation. So three-D planning have to make sure the data environment is united, which is the base of the whole function, and the information can be easily communicated. Then we must classify the function. According to make sure the implement steps, the function discreteness in the united data environment can be realized, thus guarantee the implementation effect.

\subsection{Establish the United Data Environment through the Data Planning}

Establish the enterprise model through the analysis of enterprise management function, process and activity, and then build up the commonly shared subject database of all areas by realizing the category of subject $[1,2]$.

The establishment of enterprise data environment can follow the following principle and steps:

(1) Establish the enterprise data model based on the long time structure principle. In order to establish enterprise data environment, generally following the principle: 60 percents of enterprise utility data, 30 percents of industry utility data and 10 percents of enterprise characteristic data. So the work of modeling from utility to particular will let the work begin with the most core data model structure, and the result can be inherited to guide the future appropriation model.

(2) Analyze the data in the enterprise control system ground on the control theory. The basic way is the enterprise behavior changes enterprise estate, and the changes are affected by enterprise characteristic, the result of the enterprise behavior is given out by the evaluation of enterprise performance, and the basis of the evaluation is decided by the characteristic of the enterprise. So four kinds of data can be classified, which are on the respects of enterprise state, feature, behavior and the performance $[3]$.

\subsection{Confirm the Terrace Structure by Function Planning}

The target of the function planning is identifies management function, then designs information system structure, the matrix of $\mathrm{U} / \mathrm{C}$ can give some help at this time. Finally classified planning of enterprise function can be got.

Build the enterprise terrace structure can follow the following principles and steps:

(1) Make sure the function need of terrace structure for the request of enterprise management. 
(2) The functional module and its relation follow the way of "from top to bottom", "from thick to thin" and "accurate step by step". The inside of module is high polymerization, and the relation between the modules is data coupling.

(3) Get the data by analyzing and deciding, make sure the key function component.

\subsection{Assurance the Dependence Relation by Implementing Planning}

All parts within the information system depend on each other. The demarcation should cross the function area, get the correspond process from series activities depend on the proper order and urgent degree and constitutes the implementation contents. Otherwise following problems would come out:

(1) If analyze the function one by one, it could lead to destroy the management connection of function areas, cause lacking of basic data while implement the system and produce information isolated island.

(2) If adopting each function area in every phase boosts together after detailed division of function area, it would also lead to the function dependence relation at the management system in mess, and the module implementation would lack data support.

\section{WAYS OF COLLABORATION AMONG THE THREE-D PLANNING}

Three-D planning guarantees that the informationization implement is the real tight front and tight back type of layer class push forward.

\subsection{Key-point Radiation Mode}

The key-point should be the one that is the core management process in the process of enterprise management. And it must have the following characteristics:

(1) Match the strategic target of the enterprise management to the informationization request

(2) The success of informationization at this key-point can benefit the enterprise effectively.

(3) It is placed at the point of information collection in the management, sometimes in the collection source of control information.

(4) The success of implement in this point will provide mode, data and function supports to management informationization of the series following system.

(5) The success implement at this point can drive the implement at main clue of enterprise management directly.

One way to identify the key-point is the key success factor method, which using the cause effect graph or fish bone diagrams to identify and composite the key success factors. The key-point is defined as the early part to be implemented. 
Establishing a digital comprehensive capability platform to realize the dynamic deadline control and cost control, and to build-up a manufacturing resources data standard reflecting the core competency of a shipbuilding enterprise, can improve the management level of the shipbuilding industry of our nation and make it more stronger and competitive.

\subsection{Main Clue Mode}

The main clue of the management process of enterprise must have following characteristics:

(1)The realization of the main clue management function can solve the urgent problem or bring the unexpected management result for the enterprise.

(2)The realization of the main clue can make management information much more smoothly.

(3)The main clue passes through the key-point, and the key-point is the implement base of main clue.

(4)The main clue involves several function areas for enterprises.

(5)There is a great deal of management branch connects with main clue. Its implement can provide a good foundation for the follow-up informationization.

The core business process of the general manufacturing industry informationization can be developed around three parts: production, logistics and cost. Those are all pictured as figure 1 .

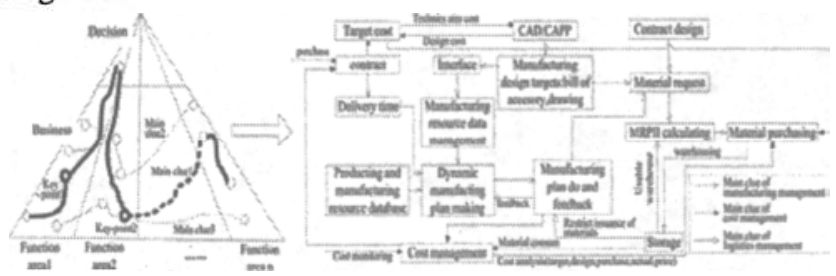

Figure 1. Main Clue Mode and Enterprise Information Core Business Flow Made of Three Management Main Clue in Manufacturing Industry

\section{CONCLUSIONS}

Three-D planning suggested in this paper can guide the enterprise effectively to pass the need to lead while being informationization planning. It starts the informationization from the parts taking effect most easily, and finally arouse the completely informationization implement totally. This project has been already applied in some typical models of complicated product manufacturing industry (dockyard), the main line of cost has already mastered currently, and the program is going very well. 
A Research on the Application of Three-D Planning of EIS in Manufacturing Industry

\section{ACKNOWLEDGEMENTS}

This research was supported by National Natural Science Foundation of China: Study on Data Model for Large-piece One-of-a-kind Production Enterprise (Grant NO. 70472005).

\section{REFERENCES}

1. J. Martine, Strategic Data Planning Methodologies (Prentice-Hall, Inc.: German, 1982).

2. C. Guo, Establish the telecommunication enterprise informationization by application of information resource planning, Journal of Dongbei University of Finance and Economics. Number 6, pp.51-53, (2004).

3. N. Ren and S. Ge, Content and course of data modeling oriented the whole shipbuilding enterprise solution, Marine Technology. Number 3, pp.5-9, (2006). 